\title{
EFEITO DA TEMPERATURA DE SECAGEM NA QUALIDADE DE GRÃOS DE AVEIA BRANCA
}

\author{
Effect of drying temperature on the quality of white oat grains \\ Leandro da Conceição Oliveira', Luiz Carlos Gutkoski², Moacir Cardoso Elias ${ }^{3}$, \\ Simone Mazzutti ${ }^{4}$, Elvio Aosani ${ }^{1}$, Jeferson Cunha da Rocha ${ }^{1}$
}

\begin{abstract}
RESUMO
Objetivou-se, com o trabalho, avaliar o efeito de diferentes temperaturas do ar de secagem na qualidade física, química e biológica de grãos de aveia branca da cultivar Albasul. Grãos de aveia (Avena sativa L.) foram submetidos à secagem estacionária com temperaturas de $25,50,75$ e $100{ }^{\circ} \mathrm{C}$ até a umidade de $13 \%$, em delineamento inteiramente casualizado. Nas amostras, foram determinados peso volumétrico, peso de 1000 grãos, germinação e vigor. Os grãos de aveia foram submetidos ao descascamento, moagem em granulometria inferior a $0,5 \mathrm{~mm}$ e avaliadas quanto a composição centesimal, atividade residual das enzimas lipase $\mathrm{e}$ peroxidase, cor e teor de beta-glicanas. O aumento de temperatura do ar de secagem intensificou a redução da qualidade biológica, expressa por meio do poder germinativo e vigor, além de provocar reduções no peso de 1000 grãos e peso volumétrico. As condições de secagem não foram suficientes para inativar as enzimas lipase e peroxidase, embora tenham provocado reduções nas suas atividades. Na secagem realizada com temperatura do ar superior a $75^{\circ} \mathrm{C}$ ocorreu redução significativa no teor de beta-glicanas.
\end{abstract}

Termos para indexação: Avena sativa, composição química, beta-glicanas, lípase.

\section{ABSTRACT}

The objective of this research was to investigate the effect of different air drying temperatures upon the physical, chemical and biological quality of white oat grains, Albasul cultivar. Oat grains (Avena sativa L.) were submitted to stationary drying at 25, 50, 75 and $100{ }^{\circ} \mathrm{C}$ until $13 \%$ of moisture, in totally randomized arrangement. In the samples, volumetric weight, weight of 1000 grains, germination and vigor were determined. The oats grains were husked, grounded at granulometry inferior to $0.5 \mathrm{~mm}$, and analyzed according to centesimal composition, residual activity lipase and peroxidase, color and content of â-glucans. Increasing the temperature of drying air intensified the reduction of biological quality, expressed through germinative power and vigor, and also led to a decrease in weight of 1000 grains and volumetric weight. The drying conditions were not sufficient to deactivate lipase and peroxidase, although they reduced enzymatic activity. Drying with air temperature above $75^{\circ} \mathrm{C}$ showed significant decrease in the â-glucans.

Index terms: Avena sativa, chemical composition, B-glucans, lipase.

\section{(Recebido em 29 de maio de 2008 e aprovado em 6 de maio de 2009)}

\section{INTRODUÇÃO}

A secagem de grãos de aveia é um procedimento crítico nas operações de pós-colheita e quando não realizada adequadamente pode provocar alterações significativas na qualidade tecnológica do grão. A secagem pode ser feita por vários métodos, desde o natural até a secagem artificial (Elias et al., 2007).

Em relação ao fluxo do produto no secador, os métodos de secagem artificial podem ser classificados em estacionário e contínuo. O método estacionário consiste em forçar o ar, por meio do produto que permanece em repouso, enquanto na secagem de fluxo contínuo, o produto em movimento é submetido a uma corrente de ar (Biagi et al., 2002; Peske et al., 2006). Independentemente do método de secagem, as características físicas, químicas e biológicas podem ser danificadas, já que os grãos são sensíveis à ação do calor (Silva et al., 1995).

A secagem estacionária intensifica a redução da qualidade biológica por expor os grãos ainda com alta umidade a um prolongado tempo em contato com o ar aquecido, acelerando desse modo a sua deterioração (Marini et al., 2005). A germinação e o vigor são utilizados como parâmetros de conservação de grãos, pois uma diminuição de seus valores indica deficiência na secagem ou no armazenamento, com consequente perda de qualidade dos grãos (Almeida Junior \& Corrêa, 2000). O emprego de altas temperaturas na secagem pode comprometer as características físicas e químicas dos grãos, ocasionando escurecimento do óleo, desnaturação protéica

\footnotetext{
'Universidade Federal de Pelotas/UFPel - Capão do Leão, RS

${ }^{2}$ Faculdade de Agronomia e Medicina Veterinária - Universidade de Passo Fundo/UPF - Km 171, Br 285 - São José - Cx. P. 611 - $99001-970$ - Passo Fundo, RS - gutkoski@upf.br

${ }^{3}$ Faculdade de Agronomia Eliseu Maciel/FAEM - Universidade Federal de Pelotas/UFPel - Capão do Leão, RS

${ }^{4}$ Universidade de Passo Fundo/UPF - Passo Fundo, RS
} 
e gelatinização do amido. Porém, não existe consenso quanto as alterações no valor nutricional dos grãos (Elias et al., 2007). Em aveia, a secagem necessita de atenção especial, em razão de o grão apresentar forte tendência à rancidez, pela presença de enzimas lipases, produtoras de ácidos graxos livres e, os produtos serem comercializados na forma integral. Os ácidos graxos de cadeias insaturadas são facilmente oxidados a hidroperóxidos, que, em reações posteriores, se transformam em uma grande variedade de compostos de baixo peso molecular, conferindo ao produto aroma e sabor desagradáveis (Gutkoski \& El-Dash, 1999). A atividade das enzimas lipases pode ser reduzida pela secagem realizada com altas temperaturas.

Objetivou-se, com o trabalho, avaliar o efeito de diferentes temperaturas do ar de secagem na qualidade física, química e biológica de grãos de aveia branca da cultivar Albasul.

\section{MATERIAL E MÉTODOS}

No trabalho, foram utilizados grãos de aveia branca (Avena sativa L.), cultivar Albasul, produzidos no Campo Experimental da Palma, na Universidade Federal de Pelotas - UFPel, município de Capão do Leão, RS. As análises químicas, físicas e físico-químicas foram realizadas no laboratório de Pós-colheita, Industrialização e Qualidade de Grãos (DCTA-FAEM UFPel) e no laboratório de Cereais do Centro de Pesquisa em Alimentação da Universidade de Passo Fundo (UPF). As análises biológicas foram realizadas no laboratório de Análise de Sementes do Departamento de Fitotecnia (FAEM-UFPel).

$\mathrm{O}$ experimento foi conduzido em delineamento inteiramente casualizado, utilizando quatro temperaturas do ar de secagem e as análises realizadas em quintuplicata. Os grãos foram submetidos à pré-limpeza, realizada em máquina piloto de ar e peneiras até valores inferiores a $1 \%$ de impurezas e ou matérias estranhas. A secagem foi realizada em sistema estacionário, adaptado em duas etapas. Na primeira etapa, as amostras com umidade inicial de $23 \%$ permaneceram estáticas na câmara de secagem e receberam ar a $25^{\circ} \mathrm{C}$ até atingirem a umidade intermediária, de 15 a $16 \%$, a fim de minimizar danos térmicos nos grãos.

$\mathrm{Na}$ segunda etapa de secagem, as amostras foram submetidas a quatro temperaturas do ar até a umidade final de $13 \%$. Na secagem 1, que serviu como testemunha, o ar permaneceu na temperatura de $25{ }^{\circ} \mathrm{C}$, enquanto nas secagens 2,3 e 4 o ar foi aquecido a 50,75 e $100{ }^{\circ} \mathrm{C}$, respectivamente, permanecendo nestas temperaturas até os grãos atingirem a umidade desejada.
Nos grãos de aveia de cada tratamento foram determinados peso volumétrico, peso de 1000 grãos, germinação e vigor. Para a realização das demais análises, a aveia foi descascada em descascador marca Imack e as cariopses moídas em moinho marca Perten, modelo 3100, em granulometria inferior a $0,5 \mathrm{~mm}$. As amostras moídas foram acondicionadas em vidros e armazenadas em ambiente com temperatura controlada de $17^{\circ} \mathrm{C}$.

$\mathrm{O}$ peso volumétrico dos grãos foi determinado pelo emprego de balança de peso hectolitro marca Dalle Molle com capacidade de $1 / 4$ de litro, sendo necessária transformação para $\mathrm{kg} \mathrm{m}^{-3}$ e balança com precisão de $0,01 \mathrm{~g}$.

$\mathrm{O}$ peso de mil grãos foi determinado, segundo normas estabelecidas pelo Ministério da Agricultura (Brasil, 1992), pela contagem de 1000 grãos e pesagem em balança analítica.

O teste de germinação foi realizado de acordo com o recomendado pelas Regras de Análises de Sementes (Brasil, 1992), utilizando 4 repetições de 50 grãos. O vigor foi avaliado pelo teste de calor sem solo, utilizando-se 4 repetições de 50 grãos.

A cor dos grãos de aveia foi determinada pelo uso do colorímetro Minolta CR 300, em acordo com o método $\mathrm{n}^{\circ}$ 14-22 da American Association of Cereal ChemistsAACC (1995). No sistema CIELab de cor, os valores L* (luminosidade) flutuam entre zero (preto) e 100 (branco), os valores de $a^{*}$ e $b^{*}$ (coordenadas de cromaticidade) variam de $-\mathrm{a}^{*}$ (verde) até $+\mathrm{a}^{*}$ (vermelho), e - $\mathrm{b}^{*}$ (azul) até $+b^{*}$ (amarelo).

Os teores de proteína bruta, lipídios, minerais, carboidratos, fibra alimentar total, fibra insolúvel e fibra solúvel foram determinados por meio de espectrofotometria do infravermelho proximal (NIR), no aparelho Perstorp Analytical NIRSystems modelo 5000, por meio do programa New Infrasoft International Software. As curvas de determinação de proteínas, lipídios e fibra alimentar foram construídas utilizando os métodos ${ }^{\circ} 991.20$ (Association of Official Analytical Chemists-AOAC, 2000), $\mathrm{n}^{\circ} 920.39$ (AOAC, 2000), n 993.19 (AOAC, 2000), respectivamente. Os teores de carboidratos foram calculados por diferença e os minerais foram determinados pela técnica convencional, ou seja, o valor encontrado correspondente ao resíduo obtido por incineração em estufa a $600{ }^{\circ} \mathrm{C}$, com destruição da matéria orgânica; baseado no método $\mathrm{n}^{\circ}$ 945.39B (AOAC, 2000). A umidade foi determinada pelo método da estufa a $105 \pm 3^{\circ} \mathrm{C}$, com circulação natural de ar, por 24 horas, de acordo com a metodologia oficial de análise de sementes preconizada pelo Ministério da Agricultura (Brasil, 1992). 
A atividade residual da enzima lipase foi determinada de acordo com a metodologia proposta por Kaur et al. (1993), sendo realizado em triplicata e o valor expresso em porcentagem de hidrólise, com base no índice de saponificação do substrato. Para a determinação da atividade residual da peroxidase, foi utilizado o procedimento preconizado por Ekstrand et al. (1992). A leitura foi realizada em espectrofotômetro, em triplicata, e uma atividade de peroxidase correspondeu ao aumento de 0,001 na absorbância a $420 \mathrm{~nm}$ minuto ${ }^{-1} \mathrm{~g}^{-1}$ de amostra.

A determinação de beta-glicanas foi determinada de acordo com metodologia proposta pela AOAC (2000), método $\mathrm{n}^{\circ}$ 995.16.

Os resultados das avaliações físicas, biológicas e químicas foram submetidos à análise de variância (ANOVA) e nos modelos significativos pelo teste $\mathrm{F}$ empregado a comparação de médias por meio do teste Tukey, ao nível de $5 \%$ de significância, com o uso do programa ANOVA do software Statistica versão $5.0^{\circledR}$.

\section{RESULTADOS E DISCUSSÃO}

Os valores de peso volumétrico e peso de mil grãos de aveia branca, cultivar Albasul, submetido a diferentes temperaturas de secagem, apresentaram diferenças significativas, sendo superior no tratamento realizado a $25{ }^{\circ} \mathrm{C}$ (Tabela 1). O aumento da temperatura do ar de secagem promoveu redução de peso volumétrico e peso de mil grãos, estando esses resultados em acordo com os obtidos por Simioni et al. (2008), ao avaliar o efeito do armazenamento controlado e não controlado, após secagem intermitente de grãos de aveia branca com temperatura de ar de 60,85 e $110^{\circ} \mathrm{C}$. Segundo Silva et al. (1995), o peso volumétrico e o peso de 1000 grãos podem sofrer alterações durante o processo de secagem. Com o emprego de temperaturas muito elevadas na secagem de um produto, o material pode ser danificado resultando em menor peso volumétrico.

A cor de um produto é definida pelo uso da escala tridimensional que descreve os diferentes componentes presentes. A luz refletida é composta de um componente escuro ou luminoso em adição a um vermelho ou verde e um componente azul ou amarelo, determinada por colorímetros ou espectrofotômetros (Coultate, 2004). Na Tabela 2, estão apresentados os valores da avaliação de cor da farinha de cariopses de aveia branca, cultivar Albasul, submetidos a diferentes temperaturas de ar de secagem. Os componentes de cor $\mathrm{L}^{*}$ (luminosidade), intensidade de $+\mathrm{a}^{*}$ (vermelho) e intensidade $\mathrm{e}+\mathrm{b}^{*}$ (amarelo) não variaram significativamente entre os tratamentos estudados.

Os resultados estão em acordo com Marini et al. (2005) que, ao avaliar a qualidade dos grãos de aveia em função da variação da temperatura do ar de secagem e da relação de intermitência, não encontraram diferenças significativas na cor dos grãos de aveia branca.

Tabela 1 - Peso de 1000 grãos ( $\mathrm{g})$ e peso volumétrico $\left(\mathrm{kg} \mathrm{m}^{-3}\right)$ em grãos de aveia branca, cultivar Albasul, submetidos à secagem com diferentes temperaturas.

\begin{tabular}{ccc}
\hline Temperatura de secagem $\left({ }^{\circ} \mathrm{C}\right)$ & Peso de 1000 grãos $(\mathrm{g})$ & Peso volumétrico $\left(\mathrm{kg} \mathrm{m}^{-3}\right)$ \\
\hline 25 & $40,79 \mathrm{a}$ & $320,46 \mathrm{a}$ \\
50 & $38,62 \mathrm{~b}$ & $318,46 \mathrm{~b}$ \\
75 & $38,47 \mathrm{~b}$ & $316,95 \mathrm{c}$ \\
100 & $37,83 \mathrm{~b}$ & $315,99 \mathrm{c}$ \\
\hline
\end{tabular}

Médias seguidas de mesma letra, na coluna, não diferem entre si ao nível de erro de $5 \%$, pelo teste Tukey.

Tabela 2 - Componentes L* (luminosidade), $+a^{*}$ (vermelho) e $+b^{*}$ (amarelo) de cor em farinha de cariopses de aveia branca, cultivar Albasul, submetidos à secagem com diferentes temperaturas.

\begin{tabular}{cccc}
\hline Temperatura de secagem $\left({ }^{\circ} \mathrm{C}\right)$ & \multicolumn{3}{c}{ Componentes de cor } \\
\cline { 2 - 4 } & $\mathrm{L}^{*}$ & $+\mathrm{a}^{*}$ & $+\mathrm{b}^{*}$ \\
\hline 25 & $58,93 \mathrm{a}$ & $5,70 \mathrm{a}$ & $31,74 \mathrm{a}$ \\
50 & $58,88 \mathrm{a}$ & $5,79 \mathrm{a}$ & $31,37 \mathrm{a}$ \\
75 & $58,79 \mathrm{a}$ & $5,80 \mathrm{a}$ & $31,19 \mathrm{a}$ \\
100 & $58,60 \mathrm{a}$ & $5,87 \mathrm{a}$ & $30,83 \mathrm{a}$ \\
\hline
\end{tabular}

Médias seguidas de mesma letra, na coluna, não diferem entre si ao nível de erro de $5 \%$, pelo teste Tukey. 
Os valores de germinação e vigor de grãos de aveia branca, cultivar Albasul submetidos a diferentes temperaturas de ar de secagem estão apresentados na Figura 1. O poder germinativo e o vigor, quando comparados ao da amostra testemunha, diminuíram em função do aumento da temperatura do ar de secagem, demonstrando, assim, que o dano térmico foi imediato nessas condições. A secagem a $100{ }^{\circ} \mathrm{C}$ promoveu as reduções do poder germinativo para $51 \%$ e do vigor para $63 \%$, enquanto que com a secagem a $75^{\circ} \mathrm{C}$ as reduções foram 33,5 e $37 \%$, respectivamente.

A aveia apresenta forte tendência a rancidez, em razão, principalmente, das enzimas lipases. Para manter o índice de acidez em níveis aceitáveis no grão de aveia é necessário que o manejo pós-colheita seja adequado, podendo ser empregadas práticas complementares como inativação pela secagem. O monitoramento da intensidade de tratamento térmico é realizado pela determinação de atividade de enzimas residuais, como a lipase e peroxidase (Marini, 2007). Apesar de o tratamento de secagem de 100 ${ }^{\circ} \mathrm{C}$ ser significativamente inferior, as temperaturas empregadas não foram suficientes para inativar a enzima lipase, mesmo sendo lábil ao calor. Os percentuais de hidrólise nos tratamentos estudados variaram entre 16,48 e $16,17 \%$ (Tabela 3).

A peroxidase é uma enzima termoestável e sua ausência, após tratamento térmico de alimentos, frequentemente é utilizada como indicador de que as demais enzimas presentes no produto foram inativadas. As temperaturas utilizadas neste estudo não foram suficientes para inativar a peroxidase, porém ocorreu redução de 7,32 $\%$ com o uso da temperatura de $50{ }^{\circ} \mathrm{C}$ e $33,57 \%$ com temperatura de $100{ }^{\circ} \mathrm{C}$. Esses resultados estão de acordo com Marini (2007) que observaram decréscimo na atividade de lípase e peroxidase com secagem estacionária a partir de $80{ }^{\circ} \mathrm{C}$.

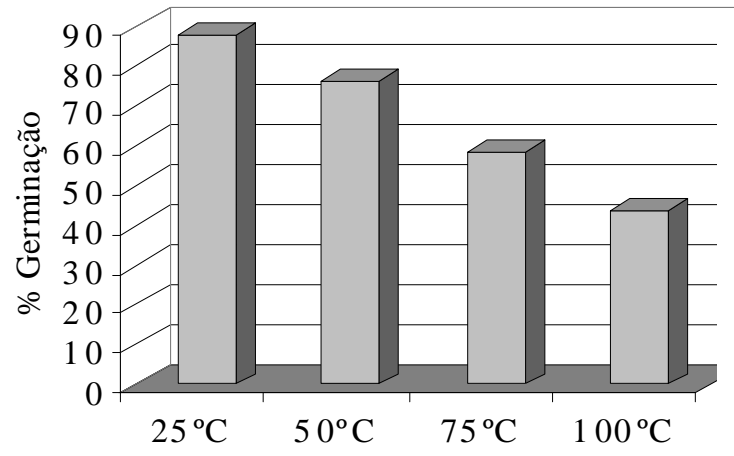

Temperatura da m ass a de grãos

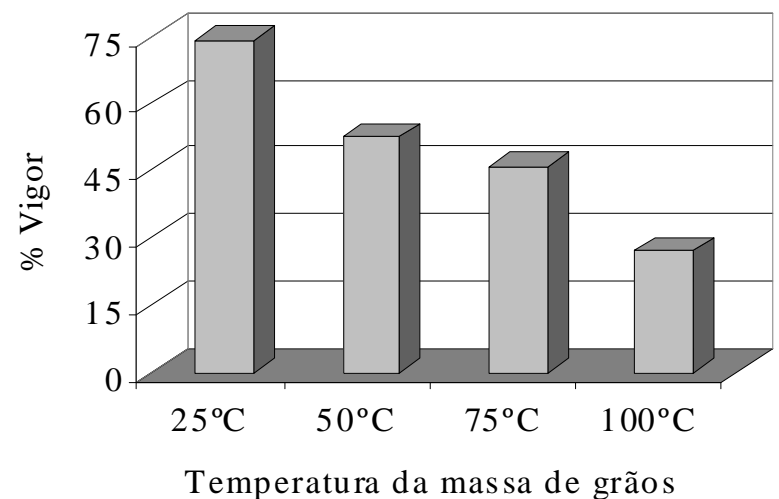

(b)

Figuras 1 - Germinação (a) e vigor (b) em plântulas normais de grãos de aveia branca, cultivar Albasul, submetido a diferentes temperaturas de ar de secagem.

Tabela 3 - Atividade residual das enzimas lipase e peroxidase em grãos de aveia branca, cultivar Albasul, submetidos à secagem com diferentes temperaturas.

\begin{tabular}{ccc}
\hline \multirow{2}{*}{ Condições de secagem $\left({ }^{\circ} \mathrm{C}\right)$} & \multicolumn{2}{c}{ Enzimas } \\
\cline { 2 - 3 } & Lípase $(\%$ de hidrólise $)$ & Peroxidase $\left(\right.$ Abs $\left.{ }_{420 \mathrm{~mm}} / \mathrm{min} / \mathrm{g}\right)$ \\
\hline 25 & $16,44 \mathrm{a}$ & $9996 \mathrm{a}$ \\
50 & $16,48 \mathrm{a}$ & $9264 \mathrm{~b}$ \\
75 & $16,40 \mathrm{a}$ & $8088 \mathrm{c}$ \\
100 & $16,17 \mathrm{~b}$ & $6640 \mathrm{~d}$ \\
\hline
\end{tabular}

Médias seguidas de mesma letra, na coluna, não diferem entre si ao nível de erro de $5 \%$, pelo teste Tukey. 
O conhecimento das proporções dos constituintes dos grãos é uma informação importante para se prever comportamentos tecnológicos e de conservabilidade dos mesmos. A aveia se caracteriza por apresentar elevados conteúdos de proteínas e gorduras, quando comparado a outros cereais (Gutkoski \& Trombetta, 1999). A composição química centesimal de grãos de aveia, cultivar Albasul, secos com diferentes temperaturas, em termos de proteína, lipídios, cinzas e carboidratos estão apresentados nas Tabelas 4 e 5. Não houve variações significativas nos teores de lipídios e cinzas com o aumento da temperatura de secagem. Para os teores de carboidratos e fibra alimentar total, foi verificada elevação significativa, enquanto que, em proteínas, amido e fibra alimentar solúvel, ocorreu redução com o aumento da temperatura de secagem. A redução de amido e fibra alimentar solúvel pode ser explicada pelo emprego de altas temperaturas que levam a complexação destes compostos (Gutkoski \& Pedó, 2000).

As beta-glicanas, uma das frações da fibra alimentar presente na aveia, são de grande importância para a saúde humana e têm gerado grande interesse em razão das respostas fisiológicas que produz (Pacheco \& Sgarbieri, 2001). A quantificação de beta-glicanas em grãos de aveia branca, cultivar Albasul, submetidos a diferentes temperaturas de ar de secagem está representado na Figura 2.

O teor de beta-glicanas diminuiu com o aumento da temperatura do ar de secagem dos grãos de aveia. As secagens realizadas com ar nas temperaturas de 50 e $75^{\circ} \mathrm{C}$ não apresentaram diferenças significativas entre si, com valores entre 3,51 a $2,89 \%$. As altas temperaturas empregadas podem ter degradado a fibra alimentar a fragmentos de baixo peso molecular ou até mesmo despolimerizando as estruturas lineares deste componente, alterando assim, a sua quantidade e, provavelmente, comprometendo o seu comportamento (Butt et al., 2008).

Gutkoski \& Trombetta (1999), estudando genótipos brasileiros de aveia encontraram concentrações de beta-glicanas entre 3,01 e 4,13\%, enquanto Sá et al. (2000), também trabalhando com genótipos brasileiros observaram valores entre 3,51 e 6,50\%. Dallepiane (1997) ao determinar o teor de beta-glicanas de cultivares de aveias nacionais, argentinos e americanos concluiu que a maior fonte de variação deveu-se a fatores genéticos. $\mathrm{O}$ teor médio de beta-glicanas dos cultivares nacionais foi de $4,50 \%$, sendo encontrado o maior valor no cultivar CTC 3, com teores similares ao da cultivar americana Milton.

Tabela 4 - Teor de umidade, proteínas, lipídios, cinzas e carboidratos de grãos de aveia branca, cultivar Albasul, submetidos à secagem com diferentes temperaturas de secagem.

\begin{tabular}{cccccc}
\hline $\begin{array}{c}\text { Condições de secagem } \\
\left({ }^{\circ} \mathrm{C}\right)\end{array}$ & Umidade (\%) & Proteínas (\%) & Lipídios (\%) & Cinzas (\%) & Carboidratos (\%) \\
\hline 25 & $13,00 \mathrm{a}$ & $16,60 \mathrm{a}$ & $6,88 \mathrm{a}$ & $2,15 \mathrm{a}$ & $61,37 \mathrm{~b}$ \\
50 & $13,00 \mathrm{a}$ & $16,29 \mathrm{~b}$ & $6,81 \mathrm{a}$ & $2,16 \mathrm{a}$ & $61,74 \mathrm{a}$ \\
75 & $13,00 \mathrm{a}$ & $16,26 \mathrm{~b}$ & $6,78 \mathrm{a}$ & $2,17 \mathrm{a}$ & $61,79 \mathrm{a}$ \\
100 & $13,00 \mathrm{a}$ & $16,25 \mathrm{~b}$ & $6,60 \mathrm{a}$ & $2,16 \mathrm{a}$ & $61,93 \mathrm{a}$ \\
\hline
\end{tabular}

Médias seguidas de mesma letra, na coluna, não diferem entre si ao nível de erro de $5 \%$, pelo teste Tukey.

Tabela 5 - Teor de amido, fibra alimentar total e fibra alimentar solúvel de grãos de aveia branca, cultivar Albasul, submetidos a diferentes temperaturas de secagem.

\begin{tabular}{cccc}
\hline Condições de secagem $\left({ }^{\circ} \mathrm{C}\right)$ & Amido $(\%)$ & Fibra total $(\%)$ & Fibra solúvel $(\%)$ \\
\hline 25 & $53,01 \mathrm{a}$ & $8,36 \mathrm{~d}$ & $3,16 \mathrm{a}$ \\
50 & $53,01 \mathrm{~b}$ & $8,73 \mathrm{c}$ & $3,00 \mathrm{~b}$ \\
75 & $53,01 \mathrm{~b}$ & $8,78 \mathrm{~b}$ & $3,05 \mathrm{~b}$ \\
100 & $52,60 \mathrm{c}$ & $9,19 \mathrm{a}$ & $2,97 \mathrm{~b}$ \\
\hline
\end{tabular}

Médias seguidas de mesma letra, na coluna, não diferem entre si ao nível de erro de $5 \%$, pelo teste Tukey. 


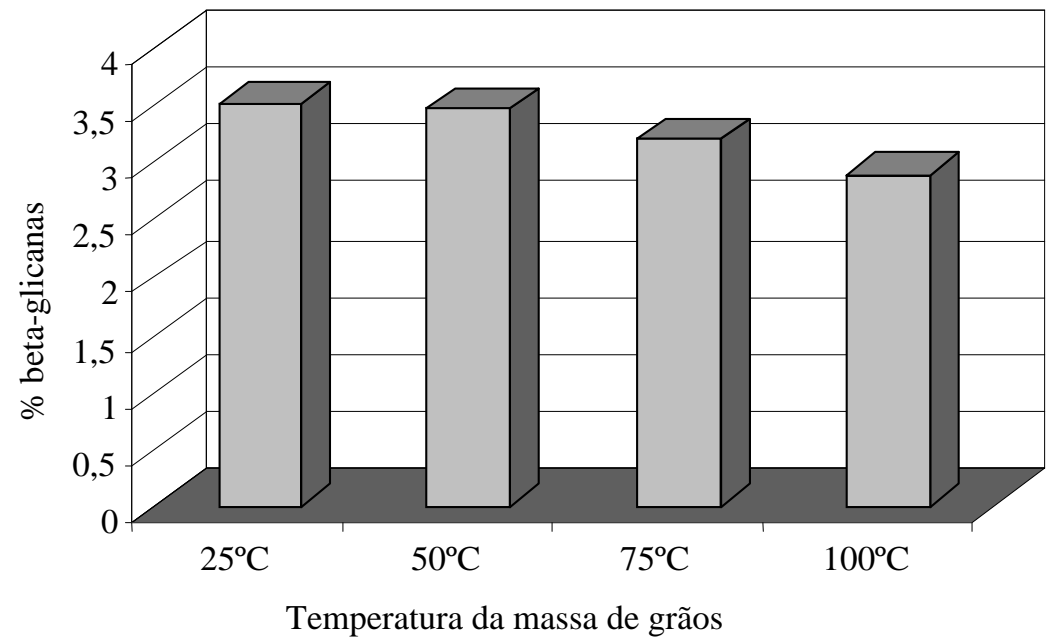

Figura 2 - Teor de beta-glicanas em grãos de aveia branca, cultivar Albasul, submetidos a diferentes temperaturas de ar de secagem.

\section{CONCLUSÕES}

O aumento de temperatura do ar de secagem intensificou a redução da qualidade biológica, expressa pelo poder germinativo e vigor, além de provocar reduções no peso de 1000 grãos e no peso volumétrico. As condições de secagem não foram suficientes para inativar as enzimas lipase e peroxidase, embora tenham provocado reduções nas suas atividades. Na secagem realizada com temperatura do ar superior a $75^{\circ} \mathrm{C}$, ocorreu redução no teor de beta-glicanas.

\section{AGRADECIMENTOS}

Ao Conselho Nacional de Desenvolvimento Científico e Tecnológico - MCT/CNPq pelo auxílio financeiro. À Capes e ao CNPq pelas bolsas de Mestrado e Iniciação Científica.

\section{REFERÊNCIAS BIBLIOGRÁFICAS}

\section{ALMEIDA JUNIOR, P.C.A.; CORRÊA, P.C. Efeitos} imediatos e latentes da secagem de sementes de feijão colhidas com diferentes níveis de umidade. Ciência e Agrotecnologia, Lavras, v.24, p.33-40, 2000.

AMERICAN ASSOCIATION OF CEREAL CHEMISTS. Approved methods of the American Association of Cereal Chemists. 9.ed. Saint Paul, 1995. v.2.

ASSOCIATION OF OFFICIAL ANALYTICAL CHEMISTS. Official methods of analysis of AOAC International. 17.ed. Gaitheersburg, 2000.
BIAGI, J.D.; BERTOL, R.; CARNEIRO, M.C. Secagem de grãos para unidades centrais de armazenamento. In: LORINI, I.; MIIKE, L.H.; SCUSSEL, V.M. Armazenagem de grãos. Campinas: IBG, 2002. v.1, p.289-308.

BRASIL. Ministério da Agricultura, Pecuária e Abastecimento. Regras para análise de sementes. Brasília: DNDV/CLAV, 1992. 365p.

BUTT, M.S.; TAHIR-NADEEM, M.; KHAN, M.K.I.; SHABI, R.; BUTT, M.S. Oat: unique among the cereals. European Journal of Nutrition, Darmstadt, v.47, n.2, p.68-79, 2008.

COULTATE, T.P. Alimentos: a química de seus componentes. 3.ed. Porto Alegre: Artmed, 2004. 368p.

DALLEPIANE, L.B. Influência das â-glicanas e amido sobre a viscosidade da aveia (Avena sativa L.). Ijuí: Unijuí, 1997. 58p.

EKSTRAND, B.; GANGBY, I.; AKESSON, G. Lipase activity in oats: distribution, $\mathrm{pH}$ dependence and heat inactivation. Cereal Chemistry, Saint Paul, v.69, n.4, p.379-381, 1992.

ELIAS, M.C.; GUERRA, R.A.; ELIAS, S.A.A.; ANTUNES, P.L. Operações de pré-armazenamento, armazenamento e conservação de grãos. In: ELIAS, M.C. Pós-colheita de arroz: secagem, armazenamento e qualidade. Pelotas: UFPel, 2007. p.147-244. 
GUTKOSKI, L.C.; EL-DASH, A.A. Extrusion cooking effects on oxidative stability of oat coarse milling product. Pesquisa Agropecuária Brasileira, Brasília, v.34, n.1, p.119-127, 1999.

GUTKOSKI, L.C.; PEDÓ, I. Aveia: composição química, valor nutricional e processamento. São Paulo: Varela, 2000. 192p.

GUTKOSKI, L.C.; TROMBETTA, C. Avaliação dos teores de fibra alimentar e de beta-glicanas em cultivares de aveia (Avena sativa L.). Ciência e Tecnologia de Alimentos, Campinas, v.19, n.3, p.387-390, 1999.

KAUR, J.; RAMAMURTHY, V.; KOTHARI, R.M. Characterization of oat lipase for lipolysis of rice bran oil. Biotechnology Letters, London, v.15, n.3, p.257-262, 1993.

MARINI, L.J. Efeito da temperatura de secagem e relação de intermitência na inativação enzimática e viscosidade de pasta de aveia. Revista Brasileira de Agrociência, Pelotas, v.13, n.1, p.55-60, 2007.

MARINI, L.J.; GUTKOSKI, L.C.; ELIAS, M.C.; MEZZOMO, N. Efeito da secagem intermitente na estabilidade de grãos de aveia branca. Brazilian
Journal of Food Technology, Campinas, v.8, n.3, p.260267, 2005.

PACHECO, M.T.B.; SGARBIERI, V.C. Fibra e doenças gastrointestinais. In: LAJOLO, F.M.; SAURA-CALIXT, F.; PENNA, E. de; MENDES, E.W. de. Fibra dietética en iberoamérica: tecnologia y salud. São Paulo: Varela, 2001. p.385-387.

PESKE, S.T.; LUCCA, O.A.; BARROS, A.C.S.A. Sementes: fundamentos científicos e tecnológicos. Pelotas: UFPel, 2006. 545p.

SÁ, R.M.; FRANCISCO, A.; OGLIARI, P.J.; BERTOLDI, F.C. Variação no conteúdo de beta-glucanas em cultivares brasileiros de aveia. Ciência e Tecnologia de Alimentos, Campinas, v.20, n.1, p.99-102, 2000.

SILVA, J.S.; AFONSO, A.D.L.; GUIMARÃES, A.C. Estudos dos métodos de secagem. In: SILVA, J. de S. Pré-processamento de produtos agrícolas. Juiz de Fora: Instituto Maria, 1995. p.105-143.

SIMIONI, D.; OLIVEIRA, M.; PAGNUSSATT, F.A.; DEUNER, C.C.; GUTKOSKI, L.C.; ELIAS, M.C. Parâmetros operacionais na secagem intermitente de grãos de aveia branca cultivar UPFA 20 Teixeirinha. Ciência e Agrotecnologia, Lavras, v.32, n.2, p.497-502, 2008. 